\title{
STRATEGI EDUKASI GIZI DAN EFEKTIVITAS MEDIA POSTER SEBAGAI IMPLEMENTASI KELUARGA SADAR GIZI (KADARZI)
}

\author{
${ }^{1)}$ Rizki Natia Wiji, ${ }^{2)}$ Imelda Fitri \\ 1) Departemen Diploma IV STIKes Al Insyirah Pekanbaru \\ Jl. Parit Indah No. 38, Pekanbaru, Riau, Website: www.stikes-alinsyirah.ac.id \\ 2) Program Studi Sarjana dan Profesi Bidan, Fakultas Kedokteran dan Ilmu Kesehatan Universitas Abdurrab \\ Jl. Riau Ujung No.37 Pekanbaru 28292 Riau \\ E-mail : ${ }^{1)}$ natiawijirizki@yahoo.co.id, ${ }^{2}$ imelda.fitri@univrab.ac.id
}

\section{Kata Kunci:}

Kadarzi, Poster, Edukasi gizi

\begin{abstract}
ABSTRAK
Rendahnya persentase Keluarga Sadar Gizi (Kadarzi) yang hanya 29,6\%. Masih tingginya kasus berat badan bayi lahir rendah sebanyak 104 kasus pada bulan JanuariJuli 2018 di RSUD Arifin Achmad, mencerminkan perilaku kurang dalam pola hidup sehat selama kehamilan.Tujuan penelitian mengembangkan media poster sebagai strategi edukasi bagi petugas kesehatan ibu bayi dan balita,serta mengetahui efektivitas media poster sebagai upaya pencapaian Kadarzi di RSUD Arifin Achmad Provinsi Riau.Jenis penelitian deskriptif analitik dengan desain quasi experiment pretest posttest one grup dengan menggunakan metode kualitatif dan kuantitatif.Sampel uji kelayakan media poster tenaga kesehatan 26 responden. Sampel uji implementasi edukasi Kadarzi ibu nifas,ibu bayi dan balita 48 responden.Strategi edukasi menggunakan media Poster dengan pesan edukasi ASI Eksklusif,timbang berat badan bayi dan balita secara teratur,makan garam beryodium,makan makanan beraneka ragam,konsumsi suplemen sesuai anjuran.Data dianalisis dengan uji t Dependen. Hasil uji efektivitas media poster menunjukkan lebih dari $80 \%$ pengetahuan responden meningkat menjadi lebih baik dari sebelumnya dan $(\mathrm{p}=0,000)$ sehingga ada pengaruh signifikan efektivitas media poster sebagai strategi edukasi bagi petugas kesehatan, ibu nifas,ibu bayi dan balita sebagai upaya pencapaian Kadarzi di RSUD Arifin Achmad Provinsi Riau. Kesimpulan media poster yang simpel,mudah dipahami dan bersifat universal efektif meningkatkan pengetahuan gizi ibu nifas, bayi dan balita.
\end{abstract}

Keywords:

Aware family nutrition, Poster, Nutrition Education

\section{Info Artikel}

Tanggal dikirim: 15 Juni 2020 Tanggal direvisi: 20 Juli 2020

Tanggal diterima: 21 Juli 2020 DOI Artikel:

10.36341/jomis.v4i2.1336.

Creative Commons Attribution-

NonCommercial-ShareAlike 4.0 International License.

\begin{abstract}
Lowness of the nutrition Awareness family (Kadarzi) percentage only 29,6\%. Low birth weight about 104 cases on January until July of 2018 at the Arifin Achmad Regional Hospital. Facing the lack behavior in the in the healthy lifestyle as long as the pregnancy. This study aimed to develop the poster media as the strategic education for the medical, maternal infant and Balita's, then knowing effectivity of the poster media as the reach effort to Kadarzi at the Arifin Achmad Regional Hospital of Riau Province. Type of the study was analytic descriptive with desain used in this study quasi experiment pretest posttest one group with qualitative and quantitative methods.The samples taken for test implementation nutrition education was 27 medical group and the sampel taken for nutritional education was 48 puerperal maternal and mothers which has the baby and infant. Educational messages developed were advice exclusive breastfeeding,weighing for children under five regularly, eating the iodine salt, eating the variant food, consuming the supplement as the patter. Data was analyzed by using $t$ Dependen test. The effectivity test outcome of the poster media Kadarzi showing more than $80 \%$ of the respondent's knowledge increased better than before and $(p=0,000)$. There was effectivity of the poster media as the education strategic for the medical, puerperal maternal and maternal which had the baby and infant as the reach Kadarzi at the Arifin Achmad Hospital of Riau. Conclusion: the nutrition education posters which were made fairly, simple, easy to understand and universal effective were able to improve the nutritional knowledge of puerperial, and infant mother
\end{abstract}

Keyword : Aware family nutrition; Poste; Nutrition Education 


\section{PENDAHULUAN}

Pemerintah terus berupaya untuk menanggulangi masalah gizi kurang yang terjadi di masyarakat melalui keluarga sadar gizi (KADARZI)[1]. Capaian masyarakat yang memenuhi kadarzi saat ini hanya $29,6 \%$ [2]. Masalah gizi jika terjadi pada ibu hamil dapat memengaruhi kesehatannya sehingga bisa melahirkan bayi berat lahir rendah (BBLR) dimana berdasarkan survei indikator kesehatan nasional (2016) terdapat 6.9\% kasus[3].

Kasus serupa tentang kejadian BBLR juga terjadi di RSUD Arifin Achmad dari Januari-Juli (2018) sebanyak 104 bayi[4]. Hal ini mencerminkan bahwa program kadarzi belum diterapkan secara maksimal.Pengoptimalan kejadian tersebut dapat diatasi melalui peningkatan pengetahuan ibu hamil melalui pendidikan kesehatan sehingga terjadi perubahan sikap dan perilaku $[5,6]$.

Pendidikan kesehatan dapat dilakukan pada ibu hamil dengan memanfaatkan media edukasi salah satunya adalah poster. Poster merupakan media informasi dalam bentuk gambar dan tulisan sehingga informasi dapat tersampaikan dengan baik[7].Media poster dapat dijadikan media promosi kesehatan untuk mempermudah penerimaan kepada subjek yang akan diedukasi. Tujuan penelitian ini mengembangkan media poster sebagai strategi edukasi bagi petugas kesehatan ibu bayi dan balita,serta mengetahui efektivitas media poster sebagai upaya pencapaian Kadarzi di RSUD Arifin Achmad Provinsi Riau

\section{TINJAUAN PUSTAKA}

Efektivitas penyuluhan dengan media poster dapat meningkatkan pengetahuan siswa di SDB 104186 Tanjung Selamat tentang kebersihan gigi [8].Sejalan dengan penelitian Hermina dan Prihatini melaporkan bahwa edukasi gizi dapat terjadi secara optimal melalui media poster sehingga terjadi peningkatan pengetahuan gizi [9].

\section{METODE}

Penelitian ini merupakan penelitian deskriptif analitik dengan metode kualitatif dan kuantitatif dan desain quasi experimentpretest posttest one grup.Penelitian telah dilaksanakan di RSUD Arifin Achmad Provinsi Riau dari bulan Mei hingga September 2019.Etik penelitian diperoleh dari Komisi Etik Fakultas Kedokteran, Universitas Riau 101/UN.19.5.1.1.8/UEPKK/2019.

Subjek dibagi ke dalam 2 kelompok untuk uji kelayakan poster di ruangan Teratai dan Ruang Gizi, yaitu tenaga kesehatan sebanyak 26 subjek, kelompok uji coba implementasi edukasi kadarzi di ruang rawat inap teratai dan poli anak melibatkan subjek ibu nifas, dan ibu yang memiliki bayi dan balita sebanyak 48 orang.

Pengambilan subjek penelitian dilakukan denganaccidental sampling[10]. Pengumpulan data dilakukan dengan memasang 5 poster indikator gizi untuk kelompok uji kelayakan posterruangan diskusi RSUD Teratai dan Gizi, kemudian subjek penelitian diberikan angket untuk menilai dan memberikan masukan atas poster yang ditampilkan. Setelah semua proses uji kelayakan poster dilakukan, maka semua masukan dari subjek direkap, kemudian poster direvisi sesuai masukan yang diberikan. Sebaliknya, pada kelompok subjek yang diberi implementasi edukasi kadarzi pengumpulan data dilakukan dengan menyebarkan kuesioner pengetahuan dengan pre/post.Kelayakan uji media poster dianalisis secara kualitatif dan data uji implementasi dianalisis dengan uji $\mathrm{T}$ menggunakan SPSS. 


\section{HASIL DAN PEMBAHASAN}

\section{Karakteristik Subjek}

Penelitian ini melibatkan tenaga kesehatan (bidan, perawat dan ahli gizi) serta ibu nifas sebagai subjek dalam penelitian ini.Karakteristik subjek disajikan pada Tabel 1.Subjek disetiap kelompok uji neniliki rentang usia 20-35, berpendidikan SMA dan DIII.

Tabel 1. Karakteristik Subjek

\begin{tabular}{|c|c|c|}
\hline $\begin{array}{l}\text { Subjek/ } \\
\text { Variabel }\end{array}$ & $\begin{array}{c}\text { Frekuensi } \\
(n=26)\end{array}$ & $\begin{array}{c}\text { Persentase } \\
(\%)\end{array}$ \\
\hline \multicolumn{3}{|c|}{ Uji Kelayakan Poster } \\
\hline \multicolumn{3}{|c|}{ Umur (tahun) } \\
\hline$<20 \&>35$ & 12 & 46,2 \\
\hline $20-35$ & 14 & 53,8 \\
\hline \multicolumn{3}{|l|}{ Pendidikan } \\
\hline SD & - & - \\
\hline SMP & - & - \\
\hline SMA & - & - \\
\hline DIII & 18 & 69,2 \\
\hline S1 & 8 & 30,8 \\
\hline $\mathrm{S} 2$ & - & - \\
\hline $\begin{array}{c}\text { Subjek/ } \\
\text { Variabel }\end{array}$ & $\begin{array}{c}\text { Frekuensi } \\
(\mathrm{n}=48)\end{array}$ & $\begin{array}{c}\text { Persentase } \\
(\%)\end{array}$ \\
\hline \multicolumn{3}{|c|}{ Uji Implementasi Kadarzi } \\
\hline \multicolumn{3}{|c|}{ Umur (tahun) } \\
\hline$<20 \&>35$ & 18 & 37,5 \\
\hline $20-35$ & 30 & 62,5 \\
\hline \multicolumn{3}{|l|}{ Pendidikan } \\
\hline SD & 2 & 4,2 \\
\hline SMP & 10 & 20,8 \\
\hline SMA & 27 & 56,3 \\
\hline DIII & 4 & 8,3 \\
\hline S1 & 2 & 4,2 \\
\hline $\mathrm{S} 2$ & 3 & 6,3 \\
\hline
\end{tabular}

Sumber: Data Primer (2019)

\section{Pengembangan Media Poster Sebagai Indikator Kadarzi}

\footnotetext{
Seluruh anggota keluarga yang mampu mengetahui, mencegah dan melindungi seluruh anggota keluarganya dari masalah kesehatan disebut juga dengan Keluarga Sadar Gizi (KADARZI) [5]
}

Pengembangan media poster sebagai sarana informasi tentang pembentukan KADARZI harus memiliki 5 indikator sebagai berikut:

a) Menyusui bayi secara eksklusif,

b) Rutin melakukan penimbangan berat badan bayi dan balita setiap bulan,

c) Konsumsi makanan yang beraneka ragam,

d) Konsumsi garam beryodium,

e) Konsumsi tablet FE dan vitamin A sesuai kebutuhan.

\section{Analisis Uji Kelayakan Poster}

Pengembangan media terdiri atas 5 poster. Hasil perbaikan dari uji kelayakan berupa poster yang telah direvisi dan dikembangkan sesuai masukan dari semua responden. Berikut marupakan poster yang telah diuji cobakan kelayakannya kepada calon penyampai pesan yaitu tenaga kesehatan di ruang teratai dan gizi, yaitu:

\section{Poster "ASI Eksklusif"}

Poster"ASI Eksklusif" informasi yang diberikan adalah ibu dianjurkan untuk memberikan hanya ASI saja sampai usia bayi 6 bulan dan dilanjutkan menyusui bayi sampai usia bayi 2 tahun. Poster juga berisi informasi tentang bagaimana posisi ibu menyusi dan tanda bayi menempel dengan benar kepada ibusaat bayi menyusu sehingga diharapkan ibu-ibu yang sudah melihat poster tersebut mengetahui bahwa bayi yang menyusui sudah melekat dengan baik atau tidak.

Masukan dan saran tentang poster yang disampaikan oleh petugas kesehatan sebagai penyampai pesan dirangkum dan diskusikan oleh tim peneliti, sehinggga didapat kesimpulan masukan untuk poster yaitu:

"Gambar bayi menyusui kurang jelas, kalimat kurang edukatif, posisi menyusui ibu harus benar, tangan harus lurus sejajar bayi dan gambar tanda perlekatan bayi menyusu di zoom (areola masuk seluruhnya ke mulut bayi, bibir atas dan bawah terbuka, dagu menempel ke payudara ibu)"

Poster "ASI Eksklusif" setelah dikembangkan disajikan pada Gambar 1. 
pada Gambar 2.

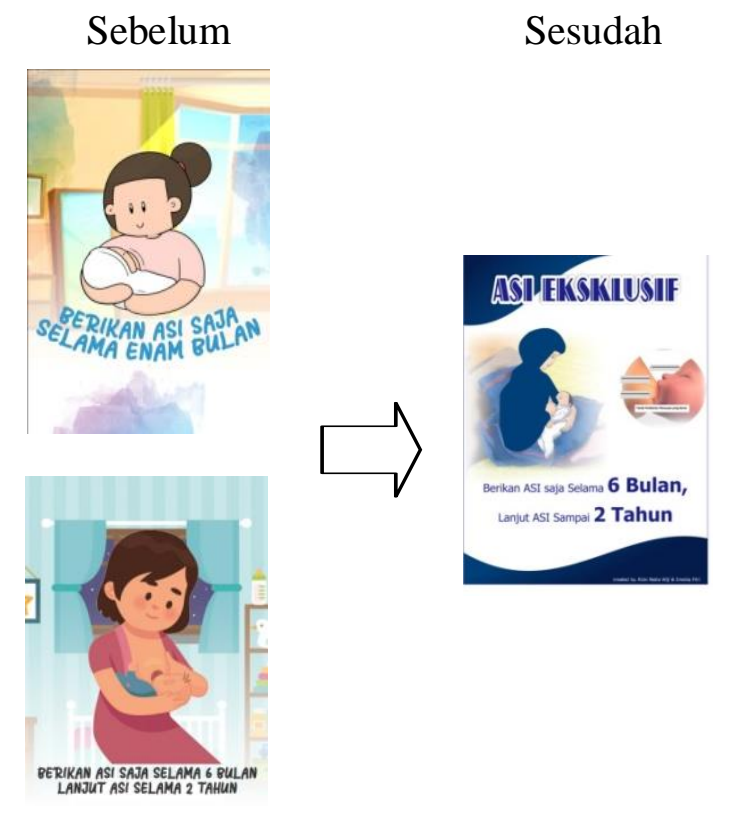

Gambar 1. Poster ASI ekslusif

\section{Poster "Timbang Berat Badan Bayi dan Balita setiap Bulan"}

Poster "Timbang Berat Badan Bayi dan Balita setiap Bulan" berisi tentang pencegahan dan penanggulangan kejadian gizi kurang dan gizi buruk pada bayi dan balita dengan melakukan penimbangan berat badan pada bayi dan balita setiap bulan di fasilitas pelayanan kesehatan.

Masukan dari petugas kesehatan dirangkum dan di diskusikan bersama tim peneliti, maka diambil kesimpulan yaitu:

"Gambar timbangan diganti sesuai timbangan bayi dan balita, kalimat kurang edukatif dan terlalu panjang, gambar kurang menarik, poster seharusnya gambar posyandu, agar ibu-ibu mengetahui kegiatan di posyandu, pada poster juga harus memperlihatkan kunjungan bayi dan balita agar sesuai dengan judul bahwa bayi dan balita yang akan dilakukan penimbangan"

Gambar "Timbang Berat Badan Bayi dan Balita" setelah dikembangkan disajikan
Sebelum
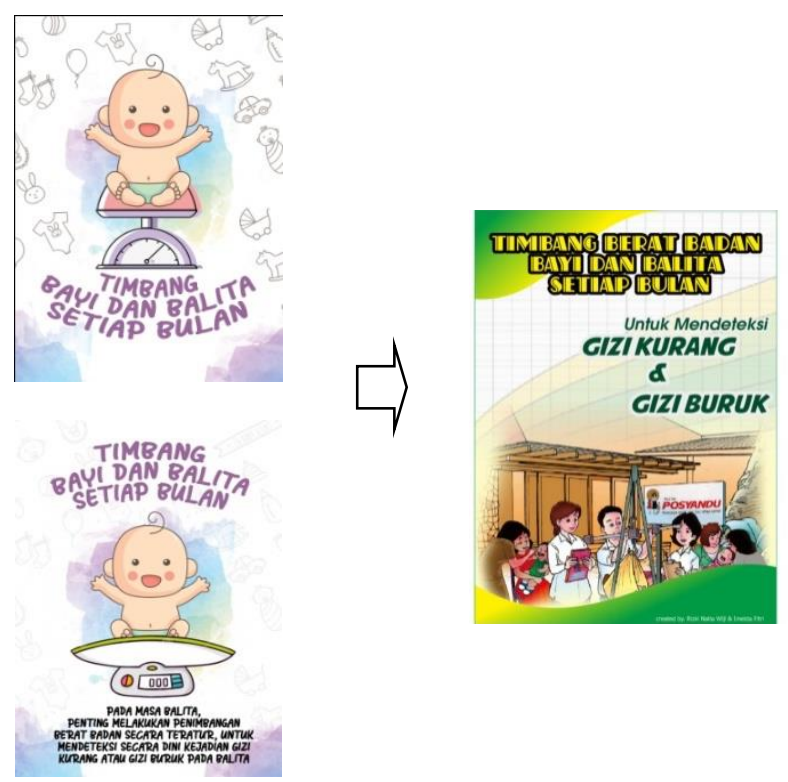

Gambar 2.Poster timbang berat badan bayi dan balita setiap bulan

\section{Poster "Makan-makanan Beraneka Ragam"}

Poster "Makan-makanan beraneka ragam"menginformasikan bahwa setiap keluarga harus mengosumsi jenis makanan yang beraneka ragam sesuai dengan kebutuhan per orangan sehingga kebutuhan gizi setiap anggota keluarga dapat terpenuhi. Masukan dan saran dirangkum sebagai berikut:

"Poster terlalu full colour, kalimat pada poster terlalu panjang, tulisan terlalu rapat sehingga tidak bisa dibaca, poster tidak menjelaskan porsi makanan yang harus dikonsumsi oleh masing-masing anggota keluarga sesuai dengan usianya. Seharusnya ada porsi untuk bayi, balita dan orang dewasa, pada poster harusnya juga menuliskan kalimat Tidak ada 1 jenis makanan yang dapat memenuhi semua zat gizi”

Poster "Makan-makanan Beraneka Ragam" setelah dikembangkan disajikan pada Gambar 3. 


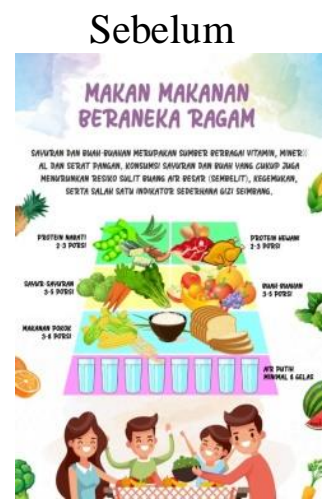

Gambar

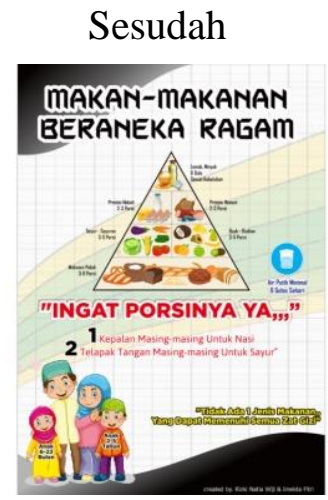

3. Poster Makan-makanan

Beraneka Ragam" setelah uji kelayakan

\section{Poster "Konsumsi Garam Beryodium"}

Poster "Konsumsi Garam Beryodium" menginformasikan bahwa garam beryodium wajib dikonsumsi setiap orang sesuai anjuran. Banyak sumber makanan lain yang juga merupakan sumber yodium yang bisa dikonsumsi jika seseorang kurang mengkonsumsi garam beryodium setiap harinya. Masukan dan saran tentang poster sebagai berikut:

"Pada poster, yang ditaburkan tidak menerangkan bahwa itu garam, takaran garam harusnya diganti sesuai dengan yang difahami oleh masyarakat, pada poster sebaiknya juga berisi cara penggunaan garam beryodium, kalimat terlalu panjang, sehingga tidak mengundang ketertarikan orang untuk membaca, dampak dari kekurangan garam, dikelompokkan saja sesuai dengan kelompok masyarakatnya. Seperti dampak kekurangan yodium pada ibu hamil, orang dewasa dan anak-anak"

Poster "Konsumsi Garam Beryodium" setelah dikembangkan disajikan pada Gambar 4
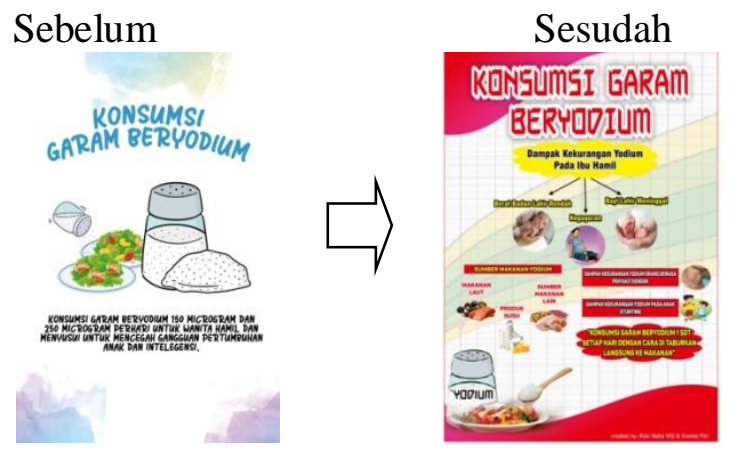

\section{Gambar 4. Poster Konsumsi Garam Beryodiumsetelah uji kelayakan}

\section{Poster "Minum Tablet Tambah Darah dan Vitamin A sesuai Anjuran"}

Poster "Minum Tablet Tambah Darah dan Vitamin A sesuai anjuran" menginformasikan bahwa setiap ibu hamil, ibu nifas dan remaja putri wajib mengkonsumsi tablet tambah darah. Banyak sumber makanan yang juga mengandung zat besi yang dapat dikonsumsi untuk mecegah anemia. Selain itu, bayi, balita dan ibu nifas juga wajib mendapatkan kapsul vitamin A yang bisa diperoleh di fasilitas pelayanan kesehatan terdekat secara percuma.

Masukan dan saran yang diberikan di rangkum dan disimpulkan oleh tim peneliti. Maka diambil kesimpulan sebagai berikut:

"Sebaiknya dalam poster bedakan mana yang menjelaskan Tablet FE dan mana yang menjelaskan tentang vitamin $\mathrm{A}$, tablet $\mathrm{FE}$ tambahkan juga remaja putri, karena remaja putri sekarang sudah wajib mengkonsumsi Tablet FE, tulisan merah dibawah yang menjelaskan tentang dosis vitamin A tidak perlu dilampirkan, karena tidak dimengerti juga oleh masyarakat, berikan saja penekanan pada waktu pemberian vitamin A, kapan diberikan serta di dapatkan dimana, pada sisi bagian kiri bawah poster diisi dengan informasi lain seperti makanan apa saja yang dapat meningkatkan zat besi atau yang mengandung zat besi”. 
Poster "Konsumsi Tablet Tambah Darah dan Vitamin A sesuai Anjuran" setelah dikembangkan dapat dilihat di bawah ini:

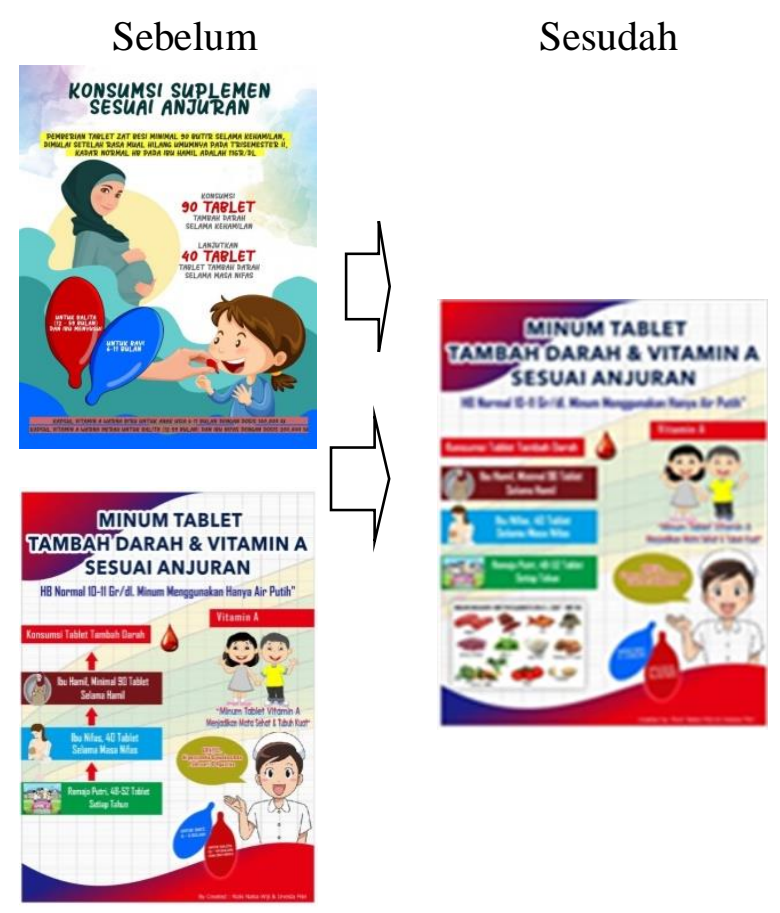

Gambar 5. Poster "Konsumsi Tablet Tambah Darah dan Vitamin A sesuai Anjuran" setelah test kelayakan

\section{Hasil Uji Kelayakan Poster}

Hasil uji Kelayakan Poster pada subject yang diberikan informasi tentang kadarzi berdasarkan table 3 menunjukkan bahwa $(81,3 \%)$ ibu memiliki pengetahuan yang baik $(10,4 \%)$ pengetahuan tetap dan $(8,3 \%)$ pengetahuan ibu menurun.

Kemudian pada tabel 4 terlihat bahwa nilai score yang awalnya 83,19 menjadi 89,09 ini menunjukkan bahwa pengetahuan ibu meningkat dari sebelumnya setelah diberikan informasi tentang Kadarzi. Hasil Uji T didapatkan $(\mathrm{p}$ value $=0,000)$ menunjukkan bahwa poster sangat efektif sebagai media informasi yang dapat diberikan oleh pelayanan kesehatan.

\section{Tabel 3Hasil uji coba implementasi media edukasi gizi di RSUD Arifin Achmad}

\section{Provinsi Riau}

\begin{tabular}{ccccccc}
\hline $\begin{array}{c}\text { Uji } \\
\text { Implementas } \\
\text { i Kadarzi }\end{array}$ & \multicolumn{3}{c}{ Perubahan pengetahuan } \\
\hline & \multicolumn{2}{c}{$\begin{array}{c}\text { Membai } \\
\mathrm{k}\end{array}$} & Tetap & \multicolumn{3}{c}{$\begin{array}{c}\text { Menuru } \\
\mathrm{n}\end{array}$} \\
$\begin{array}{c}\text { Ibu Nifas dan } \\
\text { ibu }\end{array}$ & $\mathrm{n}$ & $\%$ & $\mathrm{~N}$ & $\%$ & $\mathrm{n}$ & $\%$ \\
\cline { 2 - 7 } $\begin{array}{c}\text { mempunyai } \\
\text { bayi dan } \\
\text { balita }\end{array}$ & 39 & 81,3 & 5 & 10, & 4 & 8,3 \\
\hline
\end{tabular}

Tabel 4 Peningkatan Pengetahuan Sebelum dan Sesudah Uji Implementasi Kadarzi di RSUD Arifin Achmad Provinsi Riau

\begin{tabular}{lcl}
\hline \multicolumn{1}{c}{$\begin{array}{c}\text { Uji } \\
\text { Implementasi } \\
\text { Kadarzi }\end{array}$} & $\begin{array}{c}\text { Rerata } \pm \\
\text { SD } \\
\text { (Nilai }\end{array}$ & P \\
& Score) & \\
\hline Pengetahuan & $83,19 \pm$ & \\
Sebelum & 6,63 & 0,00 \\
Pengetahuan & $89,09 \pm$ & 0 \\
Sesudah & 6,29 & \\
& & \\
\hline
\end{tabular}

\section{PEMBAHASAN}

Masyarakat yang sehat merupakan investasi terbesar untuk meningkatkan Indeks Pembangunan Manusia[5]. Kadarzi merupakan salah satu upaya untuk memperbaiki kesehatan masyarakat atas dasar pemberdayaan masyarakat[9] . Indikator keberhasilan dapat diukur melalui penimbangan beratbadansecarateratur,(2) pemberian ASI eksklusif, makan beraneka ragam makananpenggunaan garam beryodium dan pemberian tablet tambah darah dan kapsul vitamin A sesyau dengan anjuran[5].

Melalui media poster ini terjadi peningkatan pengetahuan ibu hamil sehingga terciptanya keluarga sadar gizi.Dengan penyampaian materi sebagai berikut ASI eksklusif, penimbangan berat badan bayi dan balita setiap bulan, konsumsi makanan beranekaragam, konsumsi garam beryodium, dan konsumsitablet tambah 
darah dan vitamin A berdasarkan anjuran yang telah ditetapkan.

Ibu yang memberikan ASI eksklusif kepada bayi nya sangat dianjurkan Salah satu manfaat dari pemberian ASI eksklusif tersebut adalah mengurangirisikokekurangan zat besi. Hal ini dikarenakan zat besi pada ASI lebih mudah diserap [11]. Kegagalan dalam pemberian ASI eksklusif di masyarakat menurut Rosmalia dan Mindo (2012) menyatakan bahwa kegagalan pemberian ASI eksklusif dikarena adanya pengaruh dari dukungan keluarga dan sosial budaya[12]. Fikawati danSyafiq (2010)juga menyatakan bahwa factor predisposisi yang berpengaruh positif terhadap keberhasilan ASI eksklusif adalah pengetahuan dan pengalaman ibu, dan IMD sebagai faktor pemungkinnya serta dukungan tenaga kesehatan penolong persalinan paling sebagai faktor pendorong. Peranan media massa juga sangat berpengaruh terhadap keberhasilan dalam pemberian ASI eksklusif seperti iklan susu formula, terutama bagi ibu-ibu yang berpendidikan rendah[13, $14,15]$.

Gizi dari makanan juga berpengaruh dalam peningkatan pengeluaran ASI ibu, sehingga dapat terekspresikan melalui status gizi[16, 17]. Namun, saat ini masih ada ibu yang belum memberikan ASI ekslusif kepada bayi nya. Saat usia 4 bulan bayi juga sudah dberikan makanan tambahan seperti sereal, pati dan umbi-umbian seringkali diberikan pada usia dini sebagai akibatnya pemenuhan zat gizi menjadi rendah. Manifestasi dari keadaan tersebut ditemukannya kondisigrowth faltering yang sering terjadi pada tahun pertama kehidupan. Salah satu cara yang paling cepat untuk dapat mendeteksi kejadian growth faltering adalah dengan melakukan timbang bayi dan balita dengan teratur di Posyandu [18]. Kontribusiposyandudalam meningkatkan kesehatan bayi dan anak balita sangat besar, namun sampai saat ini kualitas pelayanan posyandu masih sangat perlu ditingkatkan[19].

Hasil penelitian sebelumnya yang dilakukan oleh Hetty dan Nursiti (2017)mengemukakan bahwa pengetahuan yang kurang, sikap ibu yang negatif, keterbatasan waktu, pekerjaan, informasi tentang posyandu, kualitas pelayanan kesehatan, tidak ada dukungan keluargadapat memengaruhi penurunan kunjungan bayi dan balita ke Posyandu[20]

Upaya pengembangan kemandirian masyarakat harus dilakukan secara berkelanjutan dengan tersedianya sarana dan tenaga kesehatan yang diperlukan.Kolaborasi lintas sektor sangat memengaruhi penyelenggaraan posyandu secara Sektor swasta harus senantiasa diingatkan tanggung jawab sosialnya untuk mendukung keberlangsungan penyelenggaraan posyandu ini agar lebih atraktif[21].

Konsumsi makanan yang beranekaragam sangat dianjurkan. Makan makanan yang beraneka ragam sangat bermanfaat bagi kesehatan. Makanan yang mengandung unsurunsur zat gizi bisa dikaji dari aspek kuantitas dan kualitasnya karena saling melengkapin kekurangan yang ada di dalam pangan tersebut Saat terjadi kekurangan atas gizi tertentu pada satu jenis makanan, tapi juga diperoleh dari makanan yang lain[22].

Irma dan Ani (2012), memperlihatkan bahwa indikator yang belum banyak dilakukan subjek adalah konsumsi makanan beranekaragam $(23,1 \%)$. Hal ini disebabkan karena sebagian besar subjek tidak bekerja pagi hingga sore sehingga tidak setiap hari menyajikan makanan dalam keluarga[23]. Penelitian lain juga menunjukkan bahwa kesadaran keluarga dalam menyediakan makanan beragam pada balita sudah mencapai $80,3 \%$ dan juga masih ada yang masih mempunyai pola makan yang kurang beragam $(19,7 \%)$ [24].

Makan-makanan yang beraneka ragamseperti protein, lemak, vitamin, mineral dan air sangat bermanfaat bagi kesehatan. Makanan yang beraneka ragam, yaitu makanan yang mengandung unsur-unsur zat gizi yang diperlukan tubuh baik kualitas maupun kuantitasnya [17, 25]. Pola makanan yang memenuhi gizi seimbang dapat menjadi indikator keragaman pangan yang dikonsumsi[26]. 
Garam beryodium dibutuhkan tubuh untuk membuat hormon yang mengatur pertumbuhan dan perkembangan kecerdasan. Penggunaannya untuk memenuhi kebutuhandapat diperoleh dari makanan laut seperti udang, tiram, sarden dan rumput laut sehingga dapat memenuhi konsumsi garam setiap anggota keluarga, terutama anak yang masih dalam proses pertumbuhan [24, 23, 27]. Beberapa defisiensi yodium dapat saja terjadi antara lain pembesaran kelenjar tiroid (gondok), myxdema, ukuran tubuh pendek dan abortus[27]. Hasil penelitian yang dilakukan Rodiah dan Abdullah (2018)melaporkan bahwa balita berstatus gizi baik pada keluarga yang menggunakan garam beryodium sebesar $80,8 \%$, sedangkan pada keluarga yang tidak menggunakan garam beryodium sebesar 0,7\%[24]. Kondisi tersebut menunjukkan bahwa penggunaan garam beryodium mempengaruhi status gizi balita.

Anemia didefinisikan sebagai kondisi dengan kadar $\mathrm{Hb}$ berada di bawah normal. Defisiensi besi seperti anemia merupakan salah satu gangguan yang paling sering terjadi selama kehamilan. Ibu hamil umumnya mengalami deplesi besi sehingga hanya memberi sedikit besi kepada janin yang dibutuhkan untuk metabolisme besi yang normal. dengan kadar hemoglobin ibu turun sampai di bawah $11 \mathrm{gr} / \mathrm{dl}$ selama trimester III [25].

Konsumsi zat besi dianjurkan untuk ibu hamil melalui makanan maupun suplemen.Tablet zat besi diberikan dengan dosis 30-60mg sehari minimal 90 butir selama kehamilan. Tablet zat besi dalam mengonsumsinya tidak boleh diminum bersama tehsusu atau kopi karena dapat menggangu mengganggu penyerapan $\mathrm{Fe}$. Ibu hamil sebaiknya mengkonsumsi tablet zat besi diantara waktu makan[17].Berdasarkan penelitian yang dilakukan oleh Irma dan Ani (2012) menunjukkan bahwa indikator kadarzi yang paling banyak dilakukan oleh ibu buruh pabrik adalah perilaku konsumsi suplemen sesuai anjuran tablet tambah darah saat hamil dan kapsul vitamin A dosis tinggi (89,7\%).
Hal ini terlihat dari sebagian besar subjek sudah mengonsumsi TTD saat hamil[23].

Sejalan dengan penelitian oleh Dianet al., (2008) menunjukkan bahwa pengetahuan sangat penting peranannya dalam menentukan kepatuhan dalam mengonsumsi tablet besi, karena berpengaruh pada perilaku ibu hamil dalam menyimpan dan mengkonsumsi tablet besi secara teratur setiap harinya[28].Zat besi (Fe) dapat diperoleh dari daging, ayam, ikan, telur, serealia tumbuk, kacang-kacangan, sayuran hijau dan pisang ambon. Sumber Fe yang berasal dari makanan hewani lebih mudah diserap oleh tubuh daripada sumber makanan nabati [25]. Menurut WHO, kebutaan anak di dunia kini telah mencapai 1,5 miliar dengan temuan setengah juta kasus baru dalam satu tahun, gangguan penglihatan ini terutama terjadi pada awal kehidupan[29]

Defisiensi vitamin A merupakan penyebab kebutaan dan meningkatnya risiko kematian pada usia anak-anak akibat penyakit infeksi yang disebabkan oleh status vitamin A yang tidak memadai. Sedangkan, status gizi balita dipengaruhi secara langsung oleh konsumsi zat gizi dan infeksi[23].Vitamin A dalam jumlah kecil untuk melindungi janin dari masalah sistem kekebalan tubuh, penglihatan yang normal, infeksi, ekspresi gen dan perkembangan embrionik. Kekurangan vitamin A dapat menyebabkan rabun senja dan cacat lahir [17]

\section{Pembahasan Hasil Uji Implementasi Media}

Teori menyatakan bahwa pengetahuan adalah hasil tahu dan ini terjadi setelah orang melakukan penginderaan terhadap suatu objek tertentu, penginderaan ini terjadi melalui panca indera manusia yakni indera penglihatan, pendengaran, penciuman, rasa dan raba. Sebagian besar pengetahuan manusia diperoleh melalui mata dan telinga [6].

Penelitian yang dilakukan oleh Hermina dan Prihatini (2015) yang berjudul Pengembangan Media Poster dan Strategi Edukasi Gizi untuk Pengguna Posyandu dan Calon Pengantin menyatakan media poster Kadarzi yang dibuat, menunjukkan bahwa $>70$ 
\% sasaran edukasi pengetahuan gizinya meningkat menjadi lebih baik dari sebelumnya,dankaderposyandumampumenyam paikanpesandenganbaikbegitujugapetugaspenyu luh perkawinan di Kantor Urusan Agama (KUA)[9]

Hal ini sejalan dengan penelitian yang dilakukan J.Hadisuyitno dkk (2017) yang berjudul Efektivitas Penyuluhan terhadap Perubahan Pengetahuan KADARZI dan PHBS ibu Balita di Desa Pulung dowo, Kecamatan Tumpang, Kabupaten Malang yang manadari hasil penelitian tersebut didapatkan uji statistik dengan nilai signifikan $(p>0,000)$ yang berarti ada perbedaan tingkat pengetahuan Kadarzi dan PHBS sebelum dan setelah dilakukan penyuluhan [30]

Penelitian yang dilakukan oleh Purniawan, Eka (2012), yang berjudul Efektivitas Media Poster dan Audio Visual (Video) terhadap Pengetahuan Ibu tentang TB Paru (Studi di Desa Winong Kecamatan Pati Kabupaten Pati) didapatkan hasil penelitian adalah terdapat perbedaan yang signifikan pada pengetahuan responden tentang TB paru sebelum dan sesudah dilakukan penyuluhan dengan media poster dengan p-value $(0,000<0,05)[31]$

Faktor-faktor yang sangat memengaruhi dalam penyuluhan kesehatan adalah dalam aspek pemilihan metode, alat bantu/media, dan jumlah kelompok sasaran, artinya untuk mendapatkan hasil penyuluhan dengan maksimal ketiga faktor tersebut sangat mempengaruhi[32]

Oleh karena itu pengetahuan ibu harus terus ditingkatkan sehingga pengetahuan dapat meningkat. Pengetahuan ini dapat dilaksanakan melalui penyuluhan-penyuluhan yang berkesinambungan baik melalui leaflet, poster dan dapat pula lewat radio spot[21]

\section{KESIMPULAN}

Peningkatan pengetahuan gizi ibu hamil sangat efektif dilakukan melalui media informasi seperti poster. Petugas kesehatan bersama dengan ibu nifas dan ibu yang mempunyai bayi dan balita dapat berperan sebagai penyampai pesan agent of change untuk perbaikan gizi bagi masyarakat dan keluarga. Diharapkan terealisasinya program Kadarzi di RSUD Arifin Achmad, sebagai upaya menurunkan kasus BBLR.

\section{DAFTAR PUSTAKA}

[1] D. Susanti, "Implementasi Program Keluarga Sadar Gizi (KADARZI) di Kota Pekanbaru," JOM FISIP Univ. Riau, vol. 5, 2018.

[2] Ridwan LF, "Faktor-faktor yang berhubungan dengan Perilaku Sadar Gizi pada Keluarga Balita di Kelurahan Karangpanimbal Kecamatan Purwaharja Kota Banjar Tahun 2010," Univ. Islam Negeri Sultan Syarif Hidayatullah, 2010.

[3] Dinkes Provinsi Riau, "Profil Kesehatan Provinsi Riau.” 2016.

[4] RSUD Arifin Achmad Provinsi Riau, "Laporan Tahunan." 2017.

[5] Depkes RI, "Pedoman Pendamping Keluarga Menuju Kadarzi," Direktorat Jenderal Bina Kesehatan Masyarakat, Direktorat Bina Gizi Masyarakat, 2007.

[6] S. Notoatmodjo, Ilmu Perilaku Kesehatan. Jakarta: Rineka Cipta, 2010.

[7] Nursalam, Konsep dan Penerapan Metodologi Penelitian Ilmu Keperawatan. Jakarta: Salemba Medika, 2003.

[8] K. S. Tahun and R. Siregar, "Efektifitas Penyuluhan Dengan Media Poster Terhadap Peningkatan Pengetahuan Tentang Kebersihan Gigi Pada Siswa / I Kelas III dan Iv Di Sdn 104186 TANJUNG SELAMAT," no. c, pp. 2012-2015, 2014.

[9] H. Hermina and S. Prihatini, "Pengembangan Media Poster dan Strategi Edukasi Gizi untuk Pengguna Posyandu dan Calon Pengantin," Bul. Penelit. Kesehat., vol. 43, no. 3, pp. 195-206, 2015.

[10] S. Notoatmodjo, Metodologi Penelitian Kesehatan. Jakarta: Rineka Cipta, 2010. [11] Rizki Natia Wiji, ASI dan Panduan Ibu 
Menyusui. Yogyakarta: Nuha Medika, 2013.

[12] R. Helmi and D. M. Lupiana, "FaktorFaktor Yang Berhubungan Dengan Pemberian Mp-Asi Dini Pada Bayi Di Kecamatan Sumberejo Kabupaten Tanggamus," J. Keperawatan, vol. VIII, no. 1, pp. 87-94, 2012.

[13] S. A. Fikawati S, "Penyebab Keberhasilan dan Kegagalan Praktik Pemberian ASI Eksklusif," Kesehat. Masy. Nas., vol. 16424, pp. 1-2, 2010.

[14] A. R. Suherni, Hesti Widyasih, Perawatan Masa Nifas. Yogyakarta: Fitramaya, 2009.

[15] M. L. Ai Yeyeh Rukiyah, Lia Yulianti, Asuhan Kebidanan III (Nifas). Jakarta: CV Trans Info Media, 2011.

[16] Desi Purwitasari dan Dwi Maryanti, Buku Ajar Gizi dalam Kesehatan Reproduksi. Yogyakarta: Nuha Medika, 2009.

[17] Imelda Fitri dan Rizki Natia Wiji, Buku Ajar Gizi Reproduksi dan Bukti. Yogyakarta: Gosyen Publishing, 2019.

[18] K. G. Dewey, "The Challenges of Promoting Optimal Infant Growth," $J$. Nutr., vol. 131, no. 7, pp. 1879-1880, 2001.

[19] Wahid Iqbal Mubarak, Ilmu Kesehatan Masyarakat Konsep dan Aplikasi dalam Kebidanan. Jakarta: Salemba Medika, 2012.

[20] H. Maria, I. Sihotang, and N. Rahma, "FAKTOR PENYEBAB PENURUNAN KUNJUNGAN BAYI DI POSYANDU PUSKESMAS LANGSAT PEKANBARU TAHUN 2016," vol. 2, no. June, pp. 168-177, 2017.

[21] A. Budi Susila Duarsa, "Faktor-Faktor Yang Berhubungan Dengan Partisipasi Ibu Untuk Menimbang Balita ke Posyandu Factors Associated with Maternal Participation for Weighing Toddler at Integrated Health Post (Posyandu)," J. Kedokt. Yars., vol. 20, no. 3, pp. 143-157, 2012.

[22] I. D. N. Supariasa, Penilaian Status
Gizi. Jakarta: EGC, 2012.

[23] A. M. Irma Aryati Octaviani, "Hubungan Pengetahuan Dan Perilaku Ibu Buruh Pabrik Tentang Kadarzi (Keluarga Sadar Gizi) Dengan Status Gizi Anak Balita (Studi Di Kelurahan Pagersari, Ungaran)," Hub. Pengetah. Dan Perilaku Ibu Buruh Pabrik Tentang Kadarzi (Keluarga Sadar Gizi) Dengan Status Gizi Anak Balita (Studi Di Kelurahan Pagersari, Ung., vol. 1, no. 1, pp. 46-54, 2012.

[24] R. Rodiah, N. Arini, and A. Syafei, "Pengaruh Perilaku Keluarga Sadar Gizi (Kadarzi) terhadap Status Gizi Balita," J. Ilmu Kesehat. Masy., vol. 7, no. 3, pp. 174-184, 2018.

[25] Waryana, Gizi Reproduksi. Yogyakarta: Pustaka Rihama, 2010.

[26] Achmad Djaeni Sediaoetama, Ilmu Gizi untuk Mahasiswa dan Profesi. Jakarta: PT Dian Rakyat, 2010.

[27] S. S. Y. Hasdianah H. R, Gizi, Pemanfaatan Gizi, Diet dan Obesitas, Pertama. Yogyakarta: Nuha Medika, 2014.

[28] D. Ramawati and W. Sejati, "FaktorFaktor Yang Mempengaruhi Kepatuha Ibu Hamil Dalam Mengkonsumsi Tablet Besi Di Desa SOkaraja Tengah, Kecamatan Sokaraja, Kabupaten Banyumas," Soedirman J. Nurs., vol. 3, no. 3, pp. 114-124, 2008.

[29] A. MB, Buku Ajar Ilmu Gizi Gizi Dalam Daur Kehidupan., 2nd ed. Jakarta: EGC, 2009.

[30] B. D. R. dan I. D. N. S. Juin Hadisuyitno, "EFEKTIVITAS PENYULUHAN TERHADAP PERUBAHAN PENGETAHUAN KADARZI DAN PHBS IBU BALITA DI DESA PULUNGDOWO, KECAMATAN TUMPANG, KABUPATEN MALANG Juin Hadisuyitno, Bastianus Doddy Riyadi dan I Dewa Nyoman Supariasa 1," Ilmiah-Vidya, vol. 25 , no. 1 , pp. 110 115, 2017.

[31] Agitya Eka Purniawan, "Efektivitas 
Media Poster dan Audio Visual (Video) terhadap Pengetahuan Ibu tentang TB

Paru(Studi di Desa Winong Kecamatan

Pati Kabupaten Pati)," pp. 1-58, 2012.

[32] Maulana HDJ, Promosi Kesehatan.

Jakarta: EGC, 2009. 